\title{
Thinking on Political Education of College Students under the Age of Big
}

\section{Data}

\author{
Shi Yun ${ }^{1}$ \\ ${ }^{1}$ Department of Ideological and Political Education, Liaoning Jianzhu Vocational University \\ Liaoyang, Liaoning Province, 111000)
}

KEYWORDS: Big Data, College Students, Political Education

\begin{abstract}
Big Data era, the ideological and political education has new features, such as: the main ideological and political education, the object is more comprehensive; the content of ideological and political education is not accurate, but mixed and has correlation. These features make the ideological and political education is facing new challenges, such as college students ideological and political education guide invasion of privacy, big data is not accurate and the loss of college students personal responsibility, which we need to change the ideological and political education workers work methods to make under the new situation and new strategies.
\end{abstract}

\section{Introduction}

Development of computer technology to a certain extent, promoted the integration of research cross between different disciplines, which also makes the ideological perspective of research methods and political education have been effectively enriched and innovation. New Communication Technology Day Especially in recent years, cloud services, networking and other new moon with, as well as to the development of academic research in the field of all walks of life brought many new topics. Under such a background, the ideological and political education workers research tentacles trend of the times and to explore the numerous changes in the network.

\section{The Concept of Big Data}

Big data, this concept was originally born in the IT field, from the level of the formation of the way, the large body of data referring to people, electronic equipment, other living things in these three interrelated aspects of the Internet, and each other influence, and large amounts of data generated in the Internet. The concept of data arrogant since been proposed, it has evolved into an information gathering from the initial simple terms and concepts, advanced process analysis and mining methods. • As Victor Meyer - Schoenberg and Kenneth • Ku Keye in his book "era of big data," a book mentioned: Big Data is a kind of Internet information by the people arising out of acts data collection and systematic analysis of flow technology, through big data analysis can be scientifically determined that people within a certain period of time behavioral tendencies and lifestyle, and thus provide accurate information to the organization, to promote science in its decision-making sex.

In just a few years time, big data has injected a tremendous force for change for each industry. We can say that the data brought social and economic benefits of increased productivity resulting growth, far beyond the technology and it is an invisible force to become a sign of the times, and showing the values and become Methodology development. Under this background, the 
opportunities and challenges faced by ideological and political education coexist, leadership and the right to speak by ideological and political education in the era of big data also need to be valued and re-examined.

\section{The Main Features of Ideological and Political Education for College Students in the Era of Big Data}

College has always been the forefront of the collision point of view, the most intense confrontation of ideas trendy positions. In today's mobile phones, computers and other Internet terminals highly popular among college students in the background, using the Internet to reveal the mood status of the mobile terminal, publishing remarks view, get news and other information has become an essential element of student life at the same time, thinking and behavior of college students, also to varying degrees by the impact of massive network of information, which makes large data objects and the environment era ideological and political education has become more complicated and presents a lot of new features.

In most humane social science research, the main research methods researchers have used questionnaires, interviews, documents, observation, etc., the use of these methods in the process, often subject to the conditions and the level of researchers surveyed restrictions in many aspects of the case sample surveys and environmental impact studies and quality.

In the ideological and political education research, researchers are often limited by choosing the sample space to carry out qualitative analysis of the reality of the problems, and then propose solutions countermeasures. However, the qualitative study of the ideological and political education, select the sample space science will directly determine whether the findings are accurate. Thus, the survey data ideological and political education in colleges and universities based on a limited sample space available and thus the conclusion is bound to be somewhat limited. In the era of big data, research questions ideological and political education in colleges and universities for ideological and political education can break choose to limit the survey, the sample space research has been infinitely expand, either covering a school students can also study all college students, in the studies and more in-depth and comprehensive, the data thus obtained and analyzed the resulting conclusions are more accurate and scientific.

In the era of big data, gathering all kinds of information and data becomes extremely easy, however, to obtain a state of mind in large data information college students' ideological and political education of colleges and universities offer a lot of convenience, but also to identify and screen information Ideological and Political Education filtration capacity of a higher requirement. In many cases, large information data is messy and difficult to accurately distinguish categories, therefore, in the course of the study in the ideological and political education, there must be some irrelevant information into the work with the collection of research data collection database, and then to accuracy of analysis results cause some interference.

From a technical perspective, these are mostly unrelated to the study of data by means of non-manual technique is difficult to eliminate, but the objectivity and integrity of the study, these data but also form an important part of a complete analysis of the results. Therefore, education should not only support the traditional concept of research away deliberately or excessive pursuit of accuracy study feature information, on the contrary, it should recognize and correct view of the existence of these mixed data of the study, and from the angle of contact and a development perspective to analyze the intrinsic link these data with the ideological trend of college students, the overall view to analyze and process the data and Ideological state, the intrinsic link student education content and other aspects, to study the information production and dissemination of the 
law, and from the essence up information for college students to explore these ideas and influence behavior, and then develop appropriate countermeasures to strengthen ideological and political education.

In the ideological and political education in the primary and key link is to grasp the thinking and behavior of college students state that college students get aspects of daily life and behavior "information." However, as mentioned above, in the traditional ideological and political education research and practical work, data sources study has two main aspects: First, college students, I filled out the questionnaire; the second is the ideological and political education in and chat or upload information issued arising college students, ideological and political education and therefore often subject to time, space and human factors such as less than satisfactory results, effectiveness is difficult to effectively guaranteed.

In the era of big data, the traditional dominant to recessive transition positive survey data backend acquisition, ideological and political education by means of big data technology can effectively avoid the sense of distance and sense of alienation brought face to face conversation with college students, and then collects all college students' aspects of network data. In these data include not only the college students daily learning, living, entertainment, time, location and other information, but also bears Students inner feelings law of development, interpersonal development trend of ideological and political consciousness and deep information. We can say that in the era of big data, the study of the ideological and political education of students by the specific conversion data generated for students, whereby the ideological and political education, and will be transformed into a real phenomenon into abstract data, thus Students to grasp the thinking and behavior development path by analyzing the data and, based on the nonlinear process of targeted education and guidance.

Ideological and political education of data mainly in the following aspects: one of the text data. Through the character of student information for text analysis; you can also see a word or phrase at a time the first time and later became the buzzword of the time, the discovery process whereby students develop thinking and ideas spread. When the character data of the ideological and political education workers can either read the text, but also the use of big data analysis software. Second is the orientation of the data. By orientation analysis, we can see that a student is the main laboratory, or in the library, or in the dormitory. We can analyze the students gone, who met with, and predict his future behavior. Third is the data communication of information. Digitization allows us to touch directly to student relationships, experiences and emotions, and student attitudes and emotions can be converted into a form that can be analyzed. Such as: Many college students in the face of circumstances romance, hanging branches like Renren, Weibo, QQ state and search engines often become the way they express ideas and seek solutions. When through data mining, data analysis, data after calculation, we can predict the behavior of what people have thought more volatile, and thus it can be targeted for ideological education or counseling. Fourth, the data of all the information, which means that all the information about students can all be digitized, are both used to read, and can be used to analyze.

\section{Challenges of Ideological and Political Education for College Students in the Era of Big Data}

Education behavior of ideological education may violate student privacy. Big Data analytics can make Ideological and Political Educators see students all aspects, and these are more or less violated students' privacy. While before we collect data, in accordance with the current privacy laws may be individual-centered thinking: Tell students what data we collect, for what purpose, and prior to collecting personal data the consent of the student's consent. However, the value of big data more 
due to its secondary use, in the era of big data, collected a lot of data at the time and is not intended for other purposes, and eventually produced a lot of innovative uses. So we can not expect the student has not informed in advance and students can not use this unity is still unknown purpose, in this process will be a violation of student privacy.

The big ideological and political education-oriented data may not be reliable. Background big data, it may make us more dependent on big data, big data but may not be so reliable. Data quality may be poor, the results of data analysis may not be objective; data analysis may contain errors or misleading; or data reach the quantification purposes. For example, use standardized tests to verify and assess the performance of its ideological incentive for school students or university teachers are unreasonable. Test whether a comprehensive test a student's comprehensive ability? Teachers can reflect whether the required quality? These are unanswerable, but the data analysis but do not see these problems. This in itself is a problem.

\section{Solutions of Ideological and Political Education for College Students in the Era of Big Data}

Protect the privacy of students. Ideological and political education of college students and artists should use big data proper guidance and formal evaluation, if the ideological and political education workers perfunctory assessment and does not reach the standards of protection measures have a negative result, then the ideological and political education workers must responsibility for such behavior. So that it can supervise the ideological and political education workers to protect student privacy.

Protect the personal responsibility of students. Big Data induce strong ideological and political isolation of those educators predicted there will be a big problem, "problem students" to reduce the risk on behalf of its ongoing review, even if they do take responsibility for the things that do not need to receive punishment such as: algorithms forecasting system identified a student after four years of college graduation is not normal. As a result, College student sent a party member and every day to help them monitor and report on the dynamic of the students to the ideological and political education workers per day. And regular contact with their parent, teacher, counselor, relatives, friends, and all-round play a supervisory role.

\section{Conclusion}

In the era of big data, ideological and political education workers work in innovative ways, more attention to the relationship between students with different information data. Big Data era is the inevitable trend of social development. Big Data and ideological and political education work in combination can help predict the ideological behavior, the effect of improving the ideological and political education, but pay attention to prevention of the risks and disadvantages, so as to make good use of big data play positive energy effect.

\section{Reference:}

[1] Victor Meyer - Schoenberg, Kenneth • Ku Keye. Era of big data [M]. Hangzhou: Zhejiang People's Publishing House, 2013.

[2] Ye Hong, (Australia) Julie White. Postmodern Humane Social Research Methods and Methodology in [J]. Southeast Academic Research, 2012 (3).

[3] Guojun Liu Shuang. Research on ideological and political education in the era of big data [J]. Theoretical observation, 2014 (1).

[4] Xing election. Challenge and Innovation of ideological and political education [J]. Ideological 
and political work, 2014 (7).

[5] Hu Shuxiang, Hsieh Yu-Jin. Ideological and political education in the era of big data [J]. Ideological Education Research, 2013 (6). 